\title{
PHYSICAL TRAINING SPECIFIC TO CADET CYCLISTS IN THE TIME TRIALS
}

\section{Narcis NEAGU ${ }^{1}$, Carmen GRIGOROIU ${ }^{1 *}$, Raluca PELIN ${ }^{1}$, Mihaela NETOLITZCHI ${ }^{1}$}

\author{
1 "Politehnica" University, Department of Physical Education and Sport - Kinetotherapy, Bucharest, Romania
} *Corresponding author: carmen_grigoroiu2015@yahoo.com

DOI: 10.35189/iphm.icpesk.2019.24

\begin{abstract}
The physical training specific to cadet cyclists in the time trials is a very extensive study theme, emphasising the need to permanently enrich the knowledge base by identifying modern training means to facilitate the improvement of sports performance. The present study aims at designing and applying a physical training programme focused on the development of endurance strength and adapted to the age specifics and the training of young cyclists specialised in the time trial. The pedagogical experiment took place between 10.01.2018-22.12.2018 and was conducted on a sample of 24 male cyclists aged 15 to 16 years from the "Olimpia" Sports Club Bucharest. The subjects of the research were divided into two equal value groups, the experimental and control ones. Both groups were assessed in the initial and final phases of the experiment in the road time trials. The experimental group followed the physical training programme proposed by us, while the control group carried out the usual training programme. At the end of the experiment, there were higher values of the results in the experimental group compared to the control group in the trials applied. This emphasises the effectiveness of the means newly introduced in the physical training programme of the experimental group. The modern means involved in the physical training of the young cyclists determined the entire methodology of improving the motor performance in the cycling competition.
\end{abstract}

Keywords: cyclists, modern means, physical training, time trial.

\section{Introduction}

In recent years, cadet high-performance cycling has had a spectacular evolution in Romania, in terms of both the results obtained in international competitions and the number of young people practicing this sport either in sports clubs or independently.

Cycling is a sports discipline with a cyclical character, which takes place on the road or indoors. The proportion of motor abilities involved in the cycling-specific effort is different depending on the distance travelled in the competition or the training exercises, but, in percentage, the largest part mostly goes to aerobic endurance.

Road cycling competitions last approximately 10-500 minutes (Sunde et al., 2010), and endurance performance is thus approximately 80-99\% dependent on aerobic metabolism (Astrand \& Rodahl, 1986). In road cycling, as in other endurance sports, the 3 major factors accounting for interindividual variance in aerobic endurance performance are considered to be "maximal oxygen consumption, lactate threshold and cycling economy" (Pate \& Kriska, 1984).

In the cycling literature, studies conducted internationally reveal that circuit weight training can improve cardiorespiratory endurance, body composition and strength in sessions taking up to 25 to 30 minutes (Gettman \& Pollock, 1981).

Analysing the typology of the physical effort, as well as the biomotor capacity involved in the time trials in cadet cyclists, we have noticed that endurance strength is the dominant motor ability, the effort zone being the aerobic one. Endurance refers to effort interspersed with breaks longer than the duration of running (Pricop, 2012). Cyclists engage in large volumes of training both indoors and on the road. However, the physical training specific to cadet cyclists in the time trials is a study topic that is less approached, both theoretically and practically. This has motivated us to document so as to find the most efficient ways to develop and highlight the biomotor potential of young cyclists in order to facilitate their sports performance.

It is well known that sports performance cannot be achieved without the on-going improvement of sports training strategies in line with the latest trends in the modern training process for each level of training. Therefore, knowing and highlighting the biomotor potential of the human body is a priority from the first stage of the cycling training.

\section{Purpose of the study}

This study aims at designing and applying a physical training programme focused on the development of endurance strength and adapted to the age specifics and the training of young cyclists specialised in the time trial. 


\section{Research hypothesis}

The efficiency-based systematisation of means specific to the development of physical training, taking into account the somatic-functional particularities of the cadet cyclist and the requirements of the sports performance training, can facilitate the increase in the training efficiency with direct reflection on the sports performance.

\section{Material and Methods}

The research methods used to achieve the proposed tasks were: bibliographic study, direct and indirect observation, experimental method, test method, statistical method and graphical method (Epuran, 2005).

The research tools consisted in recording the time of each cyclist in the 1-km and 10-km distance time trials.

\section{Subjects, place and conditions of the research}

The experimental research included a sample of 24 male subjects practicing cycling for 7-8 years, from the "Olimpia" Sports Club Bucharest. The athletes were divided into two equal value groups as follows: 12 subjects in the experimental group and 12 subjects in the control group. The activities necessary to carry out the experiment took place at both the "Olimpia" Sports Club Bucharest and the National Arena Stadium.

Prior to initiating the research, the subjects were verbally informed on the peculiarities of the tests used and agreed on the way the experiment was conducted.

\section{Research development}

The research was conducted during one year of training, in the period 10.01.2018-22.12.2018, as follows:

- between 10-12.01.2018, the initial test of the two groups took place by applying two specific trials performed on the road over a distance of $10 \mathrm{~km}$ and $1 \mathrm{~km}$ and it was designed in order to find out the initial values of the studied parameters;

- between 15.01.-20.12.2018, the designed training programmes were applied. In the preparation of this group, we used the independent variable of our research, namely the programmes for developing the endurance strength of cadet cyclists.

- on 22.12.2018, the final assessment of the two groups of subjects took place. The final test assessed their sports performance in specific road trials over the distances of $10 \mathrm{~km}$ and $1 \mathrm{~km}$.

\section{Research content}

The strategy applied in the experiment was based on both the hierarchy of specific means for developing endurance strength during some training programmes and the criterion of the effect produced on the indicators of optimisation for the physical training of the cadet cyclists.

The methodological process used was the circuit, which involves passing the athletes from one workshop to another working on a number of muscle groups equal to the number of workshops.

The experimental group performed 6 training sessions per week, in which 30-40 minutes were allocated to the operational structures proposed to be experimented, and the control group worked the usual programme with the same number of workouts per week. We exemplify in Table 1 a sequence of the programme designed by us and applied to the experimental group.

Table 1. Specific physical training programme

\begin{tabular}{lccccc}
\hline \multicolumn{1}{c}{ Means } & $\begin{array}{c}\text { No. of } \\
\text { repeats }\end{array}$ & $\begin{array}{c}\text { Nature of } \\
\text { breaks }\end{array}$ & $\begin{array}{c}\text { No. of } \\
\text { series }\end{array}$ & Intensity \\
\hline \multicolumn{1}{c}{1} & 2 & 3 & 4 & 5 \\
Pedalling on the home trainer & $25^{\prime}$ & Active & 1 & $90 \%$ \\
Lying prone, trunk extension & $45-50$ & Active & 1 & $95 \%$ \\
Lying supine, press pushes for thighs 45-50 kg & $65-70$ & Active & 1 & $90 \%$ \\
Jumps over the gymnastics bench & $45^{\prime \prime}-1^{\prime}$ & Active & 1 & $95 \%$ \\
Helcometer pull-ups with 40 kg & $45-50$ & Active & 1 & $90 \%$ \\
Lying supine, vertical trunk lifts & $1^{\prime}-10^{\prime \prime}$ & Active & 1 & $90 \%$ \\
Pedalling on the roll & $20^{\prime}$ & Active & 1 & $95 \%$
\end{tabular}


Dumbbell chest press with $60 \mathrm{~kg}$

Lying prone, trunk extension

Push-ups

$\begin{array}{ll}25-30 & \text { Active } \\ 40-45 & \text { Active } \\ 45-50 & \text { Active }\end{array}$

Active

1

$90 \%$

$90 \%$

$90 \%$

\section{Results}

The dynamics of the results obtained in the two assessments (initial and final) is shown in Tables 2 and 3 and refers to the value of the statistical parameters determined (arithmetic mean, standard deviation, mean difference and coefficient of variation) through the two time-contest trials over the distances of $1 \mathrm{~km}$ and $10 \mathrm{~km}$.

We used the independent Student's t-test to determine the authenticity of the differences between groups and the significance of the progression by comparison with the significance threshold for the number of cases (n), according to Fisher's Table. In our case, $\mathrm{n}=12$, and the critical $\mathrm{t}$-value is $\mathrm{t} \geq 2.074$ at the $\mathrm{p}$-value $<0.05$.

Table 2. Comparative results of the experimental group (EG) and control group $(C G)$ in the initial test

\begin{tabular}{|c|c|c|c|c|c|c|c|c|}
\hline \multirow{3}{*}{ Test } & \multirow{3}{*}{$\mathrm{n}$} & \multicolumn{7}{|c|}{ Statistical indicators } \\
\hline & & EG & $\mathrm{CG}$ & EG-EC & EG & CG & & \\
\hline & & Mean/ \pm SD & Mean/ \pm SD & Mean dif. & $\mathrm{CV} \%$ & $\mathrm{CV} \%$ & $\begin{array}{c}\text { Independent } \\
\text { t-test }\end{array}$ & $\mathrm{p}$ \\
\hline $10 \mathrm{~km}$ (in sec) & 12 & $23.706 / 0.37$ & $23.703 / 0.39$ & 0.003 & 1.56 & 1.64 & 0.0214 & $>0.05$ \\
\hline $1 \mathrm{~km}$ (in sec) & 12 & $1.241 / 0.05$ & $1.240 / 0.52$ & 0.001 & 4.02 & 41.93 & 0.4166 & $>0.05$ \\
\hline
\end{tabular}

In the initial phase of the experiment, the experimental and control groups obtained similar results (Table 2) in both competition trials $(10 \mathrm{~km}$ and $1 \mathrm{~km})$.

In the $10-\mathrm{km}$ distance time trial, the arithmetic mean of the experimental group was $23.706 \mathrm{sec}$, and for the control group, $23.703 \mathrm{sec}$, the mean difference being $0.003 \mathrm{sec}$. The coefficient of variation (CV) indicates increased homogeneity for both groups, namely $1.56 \%$ (EG) and $1.64 \%$ (CG).

In the $1-\mathrm{km}$ distance time trial, the arithmetic mean of the experimental group was $1.241 \mathrm{sec}$, and for the control group, $1.240 \mathrm{sec}$, the mean difference being $0.001 \mathrm{sec}$. The coefficient of variation (CV) indicates increased homogeneity for the EG (4.02\%) and non-homogeneity of $41.93 \%$ for the CG.

As a result of applying the independent Student's t-test, we concluded that there are no statistically significant differences, in the initial phase of the experiment, between the values of the two groups for both the 10-km time trial $(\mathrm{t}=0.0214, \mathrm{p}>0.05)$ and the $1 \mathrm{~km}$ time trial $(\mathrm{t}=0.4166, \mathrm{p}>0.05)$.

In Figure 1, we observe that, in the initial phase of the research, the two groups have close values of the arithmetic mean in both trials.

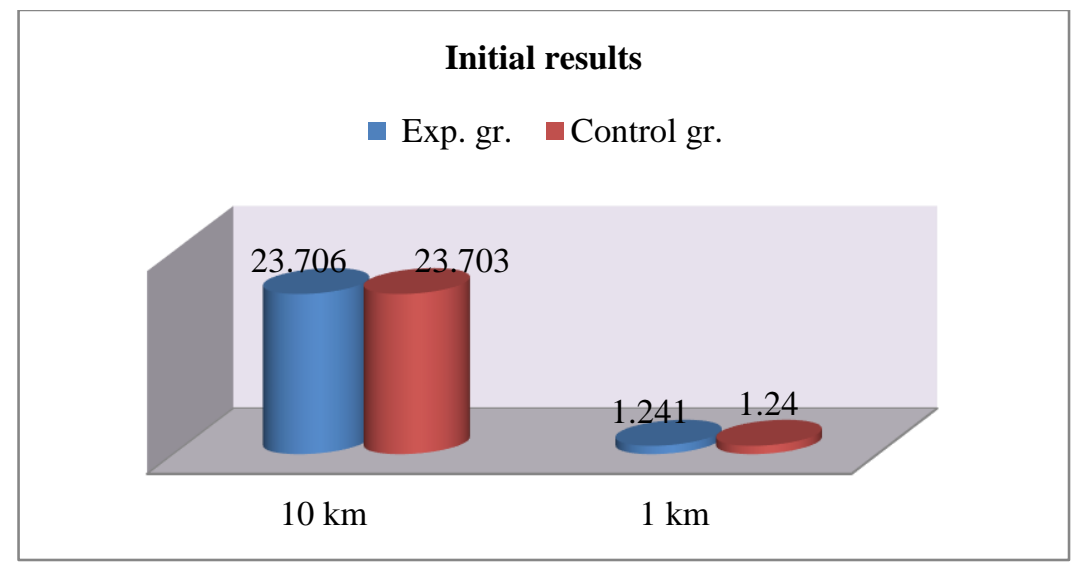

Figure 1. Means obtained by the experimental group (EG) and control group (CG) in the initial test

By comparing the average results obtained by the two groups at the end of the experimental research, the significance of the training differences in favour of the experimental group (Table 3) is emphasised. 
International Proceedings of Human Motricity/ ICPESK 2019

Supplementary Issue of Discobolul - Physical Education, Sport and Kinetotherapy Journal, 2019

Table 3. Comparative results of the experimental group $(E G)$ and control group $(C G)$ in the final test

\begin{tabular}{|c|c|c|c|c|c|c|c|c|}
\hline \multirow{3}{*}{ Test } & \multirow{3}{*}{$\mathrm{N}$} & \multicolumn{7}{|c|}{ Statistical indicators } \\
\hline & & EG & CG & EG-EC & EG & CG & & \\
\hline & & Mean $/ \pm$ SD & Mean $/ \pm \mathrm{SD}$ & Mean dif. & CV \% & $\mathrm{CV} \%$ & $\begin{array}{l}\text { Independent } \\
\text { t-test }\end{array}$ & $\mathrm{p}$ \\
\hline $10 \mathrm{~km}$ (in sec) & 12 & $23.372 / 0.21$ & $23.573 / 0.36$ & -0.201 & 0.89 & 1.52 & 1.5563 & $>0.05$ \\
\hline 1 km (in sec) & 12 & $1.170 / 0.03$ & $1.230 / 0.04$ & -0.06 & 2.56 & 3.25 & 3.7253 & $<0.05$ \\
\hline
\end{tabular}

At the end of the experiment for the $10-\mathrm{km}$ distance time trial, the arithmetic mean of the experimental group was $23.372 \mathrm{sec}$, and that of the control group, $23.573 \mathrm{sec}$, with a mean difference of $0.201 \mathrm{sec}$. The coefficient of variation $(\mathrm{CV})$ indicates increased homogeneity for both groups of subjects (EG - 0.89\%, CG - 1.52\%). The independent Student's t-test indicates that there are no statistically significant differences between the values of the two groups $(\mathrm{t}=1.5563, \mathrm{p}>0.05)$ in the final phase of the experiment.

In the $1-\mathrm{km}$ distance time trial, the arithmetic mean of the experimental group was $1.17 \mathrm{sec}$, and that of the control group, $1.23 \mathrm{sec}$, the mean difference being $2.56 \mathrm{sec}$. The coefficient of variation $(\mathrm{CV})$ indicates increased homogeneity for both groups of subjects (EG - 2.56\%, CG - 3.25\%). The independent Student's t-test indicates that there are statistically significant differences between the values of the two groups $(t=3.7253, p<0.05)$ in the final phase of the experiment.

At the end of the experiment, higher values of the arithmetic mean of the experimental group were recorded compared to those of the control group in the two competition trials (Figure 2). This emphasises the efficiency of the means newly introduced in the training of the experimental group.

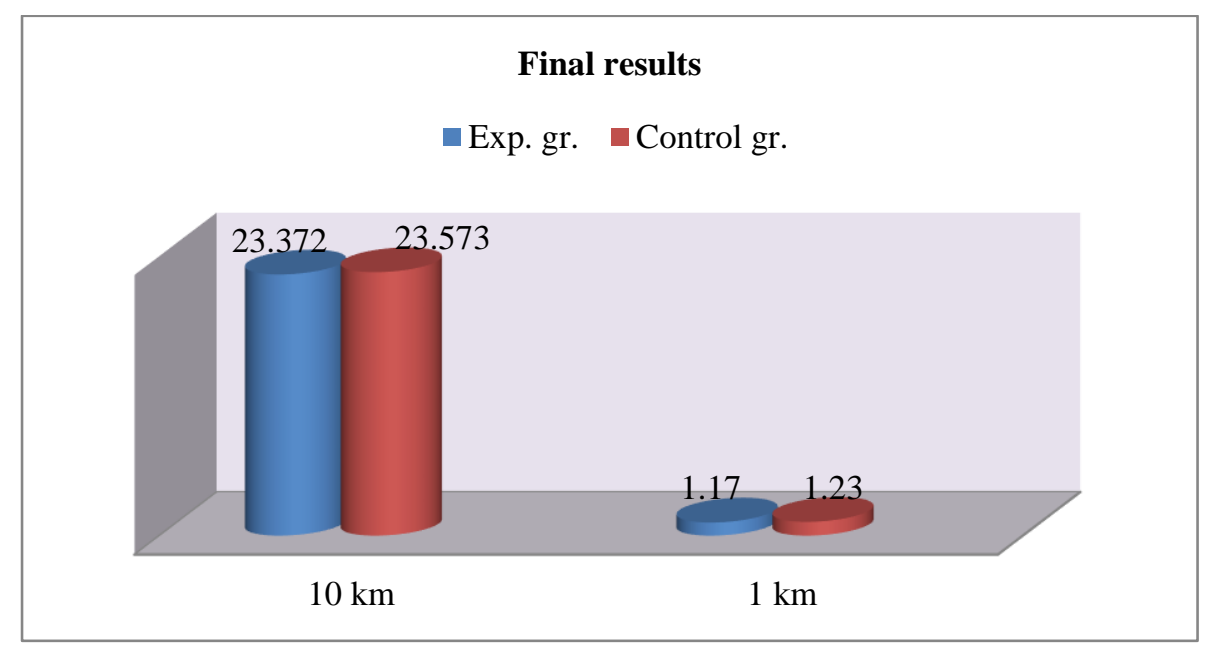

Figure 2. Means obtained by the experimental group (EG) and control group (CG) in the final test

\section{Conclusion}

After applying the experimental programme focused on improving the physical training of young cyclists, materialised in practice on the basis of the sports training planning documents, we noticed the significant progress of the experimental group compared to the control group in one of the two trials performed.

These differences can be explained by the different training programmes followed by the two groups, which confirms that the independent variable applied to the experimental group has made the difference in the training, the research hypothesis being confirmed.

The use of a wide range of rationalised and standardised means in special training programmes can facilitate the increase in the level of endurance strength development and implicitly in the physical training of cadet cyclists.

The experimental validation of the work hypothesis expresses the efficiency of the newly introduced means in organizing and conducting the training performed with the experimental group, which leads to improving the motor performance involved in the cycling competition. 
Endurance strength is one of the most important motor components in cycling, and its optimal development is essential in achieving sports performance.

\section{Authors' Contributions}

All authors contributed equally to this study and should be considered as main authors.

\section{References}

Astrand, P. O., \& Rodahl, K. (1986). Textbook of work physiology. New York: McGraw-Hill.

Epuran, M. (2005). Metodologia cercetării activităţilor corporale [Research methodology for bodily activities] (Ed. a 2-a). Bucureşti: FEST.

Gettman, L. R., \& Pollock, M. L. (1981). Circuit weight training: A critical review of its physiological benefits. The Physician and Sportsmedicine, 9(1), 44-60. https://doi.org/10.1080/00913847.1981.11710988

Pate, R. R., \& Kriska, A. (1984). Physiological basis of the sex difference in cardiorespiratory endurance. Sports Medicine, 1(2), 87-98. https://doi.org/10.2165/00007256-198401020-00001

Pricop, A. (2012). Obiectivarea metodelor care condiţionează dezvoltarea calităţilor motrice de bază în fotbalul universitar [Objectification of the methods that condition the development of basic motor skills in university football]. Marathon, $\quad$ IV(2), $\quad 92-95 . \quad$ Retrieved $\quad$ from http://www.marathon.ase.ro/pdf/vol4/42/14\%20Adrian\%20Daniel\%20Pricop.pdf

Sunde, A., Storen, O., Bjerkaas, M., Larsen, M. H., Hoff, J., \& Helgerud, J. (2010). Maximal strength training improves cycling economy in competitive cyclists. Journal of Strength and Conditioning Research, 24(8), 2157-2165. https://doi.org/10.1519/JSC.0b013e3181aeb16a 